\title{
Processos de Mentoring e Shadowing como Ferramentas de Gestão do Conhecimento para a Socialização de Novos Servidores no Departamento de Polícia Federal
}

\author{
luciano D'Escragnolle Cardoso
}

DEPARTAMENTO DE POLÍCIA FEDERAL.

○次

\begin{abstract}
RESUMO
O propósito deste artigo é investigar as principais dificuldades de socialização organizacional enfrentadas por servidores recém-empossados no Departamento de Polícia Federal, com o objetivo de apontar a possibilidade de utilização dos processos de mentoring e shadowing como ferramentas de gestão do conhecimento orientadas à aprendizagem organizacional, atuando através do compartilhamento sistematizado de experiências e do incentivo à socialização de conhecimentos entre antigos e novos servidores. Para tanto, apresenta o resultado de uma pesquisa qualitativa introdutória ao tema realizada através de entrevistas com servidores policiais empossados no órgão a partir do concurso público realizado no ano de 2004, visando apontar as dificuldades mais comuns de socialização (ambientação) por estes vivenciadas, e como os processos de mentoring e shadowing podem contribuir para a redução das barreiras enfrentadas pelos servidores entrantes no órgão, bem como atuar na disseminação da cultura interna de aprendizagem e gestão de conhecimento, agregando os conhecimentos produzidos como um incremento à memória organizacional.
\end{abstract}

Palavras-Chave: Shadowing. Mentoring. Gestão do conhecimento. Aprendizagem organizacional. Memória organizacional. Socialização organizacional.

\section{INTRODUÇÃo}

No amplo universo das ciências sociais, muito se discute atualmente sobre os temas da gestão do conhecimento e gestão de pessoas, suas ferramentas e aplicações, onde cada vez mais se percebe que o conhecimento ganha importância como um recurso organizacional, frente à ampla competitividade empresarial e à busca contínua de vantagem competitiva. Neste contexto, po- 
demos assumir o fato de que vivemos em um período singular na história, traduzido por inúmeros autores contemporâneos pelo termo "pós-modernidade".

Ao buscar as características preponderantes desta "pós-modernidade" contemporânea, alguns conceitos fundamentais certamente serão apontados, tais como a globalização econômica e cultural; a presença de um ambiente conjuntural pautado pela incerteza; a grande competição entre organizações em busca de mercados; as modificaçôes qualitativas das forças de produção, ressaltadas através do surgimento do "trabalhador do conhecimento" e, consequentemente, de sua influência na transformação das relações de trabalho.

Em uma economia onde a única certeza é a incerteza, a fonte certa de vantagem competitiva duradoura é o conhecimento. Quando os mercados transformam-se, as tecnologias proliferam, os competidores multiplicam-se e os produtos tornam-se obsoletos quase do dia para a noite, as empresas bem sucedidas são as que criam novos conhecimentos, disseminam-no amplamente pela organização e o incorporam rapidamente em novas tecnologias e produtos (NONAKA; TAKEUSHI, 2008, p. 39).

Partindo-se desta premissa, a busca pelo entendimento das características de nossa sociedade atual, palco de tantas e abruptas mudanças, passa, necessariamente, pela busca dos momentos históricos iniciais destas transformações. Decerto, o progresso científico, impulsionado pelas mudanças sistemáticas do significado e emprego do conhecimento, é parte integrante de todas as revoluções sociais que se passaram nos últimos séculos, cujas consequências refletem o objeto do presente estudo.

Estas mudanças históricas, representadas principalmente pela Revolução Científica do século XVII, traduziram a ruptura entre a idade média e a modernidade a partir de um novo entendimento da Ciência, formado pela unidade entre o conhecimento científico da tradição grega (episteme) e a técnica (techne), impondo um sentido de utilidade prática, preponderante para o surgimento da tecnologia. “(...) então, começando depois de 1700, e em um período incrivelmente breve de cinquenta anos - a tecnologia foi inventada” (DRUCKER, 2001, p. 20).

A própria palavra tecnologia, como aponta Drucker em outro trecho de seu trabalho (2001, p. 20), trata-se de um manifesto, ao combinar os termos "techne", ou o mistério de uma arte, ao sufixo grego "logia", o estudo sistemático e intencional. Desta forma, a partir da expansão da tecnologia, 
formou-se o ambiente de mudanças que, em um contexto de ampla complexidade, contribuiu para a formação de nossa sociedade contemporânea.

Assim, nesta denominada "sociedade pós-moderna", caracterizada pelo elevado grau de incerteza, de grande velocidade de mudanças e, consequentemente, de ampla instabilidade, a sobrevivência das organizações advém principalmente da forma pela qual estas exercem o poder de adaptação aos novos padróes de realidade postulados, baseados na quebra de paradigmas, na mudança das relações de trabalho e na convivência e compreensão de paradoxos (como micro e macro, autonomia e controle), onde, de acordo com Nonaka e Takeushi (2008, p. 18), "uma das principais razões pelas quais as empresas fracassam, atualmente, é sua tendência de eliminar os paradoxos, prendendo-se a antigas rotinas criadas pelo seu sucesso anterior".

Neste contexto, aplicando um grau comparativo entre os sistemas privado e público, neste último a necessidade adaptativa é igualmente relevante, não pela questão de sobrevivência organizacional, uma vez que não permanece incorporado sob um modelo Biológico-Darwinista, mas sim para a manutenção ou melhoria da eficiência em sua prestação de serviços, sob pena de conservação de uma estrutura inapropriada, burocrática, pouco competitiva, com alto índice de turnover de servidores e baixa inovação, inibidores de um sistema de gestão eficiente.

Para tanto, possuir uma visão holística destes fatores é condição sine qua non para compreensão da sociedade contemporânea e seus efeitos, formados sobretudo pelas interconexões entre atores, variáveis e demais componentes do universo social. Neste contexto, “(...) pensamento sistêmico e prática sistêmica são competências-chave no processo de aprendizagem de como lidar com situações de complexidade do "mundo real" (SCHLINDWEIN, 2005).

Embora estes parágrafos introdutórios possam parecer aparentemente fora do escopo proposto, são de fundamental importância para o entendimento do ponto-chave deste estudo, o qual surge como uma das consequências deste conjunto de mudanças tecnológicas e sociais: as mudanças qualitativas das forças de trabalho e de sua relação com a organização, como fatos que justificam a evidência em que os temas da "gestão do conhecimento" e "gestão de pessoas" são abordados nas teorias atuais da administração. 
Esta mudança qualitativa das forças de trabalho, traduzida pela paulatina migração de um trabalho manual para um exercício tipicamente intelectual (principalmente no século XX, onde pela primeira vez utilizou-se o termo "trabalhador do conhecimento"), pode ser considerada uma das mudanças sociais mais importantes do último século, uma vez que induz as organizações a adotar novas estratégias de gestão para a manutenção do potencial competitivo (da organização mecanicista para a organicista; do gerente-capataz ao líder; da verticalização para a estrutura horizontal e transversal, da decisão centralizada para a compartilhada etc.).

Segundo Drucker (2001, p. 13), “a única vantagem competitiva significativa é a produtividade do trabalhador de conhecimento. E essa está em grande parte nas mãos desse trabalhador, e não nas mãos da administração". Desta forma, ao perceber a relevância deste ativo intangível, modificam-se os modelos de gestão organizacional no tocante à valorização do conhecimento, de criação de uma memória coletiva e de processos de aprendizagem.

Para Fleury e Oliveira Jr. (2002, p. 133), os “temas como capital humano, capital intelectual, inteligência competitiva e gestão do conhecimento vêm se tornando palavras de ordem nas organizações, com diferentes significados e aplicações".

Assim, o trabalhador que outrora dependia dos meios de produção disponibilizados pela organização para seu exercício laboral, hoje os carrega consigo, em um fenômeno que justifica o atual índice de mobilidade de funcionários que apresentam diversas empresas, e traz à tona os temas da gestão do conhecimento e gestão de pessoas, uma vez que as organizaçôes precisam tanto atrair e reter seus funcionários (onde se insere a ambientação - ou socialização), quanto produzir continuamente e disseminar conhecimentos para a perpetuação de sua existência (onde se integra a aprendizagem e memória organizacional).

Conforme assinalam Fleury e Oliveira Junior (2002, p. 133), “organizações que enfrentam condições de incerteza, ambientes em mudança e intensa competição devem ser capazes de aprender e, ao fazê-lo, desenvolver novos conhecimentos", onde "já se tornou lugar-comum afirmar que o recurso mais valioso em um cenário de mudança e crescente complexidade são as pessoas" (FLEURY; OLIVEIRA JR., 2002, p. 133). 
No caso da questão-tema deste estudo, cuja organização pesquisada atua diretamente na prestação dos serviços de segurança pública, o fator de efetividade na condução de suas políticas se torna ainda mais fundamental, uma vez que, embora assumindo toda a complexidade envolvida (onde se integram amplas questões de natureza social, política e econômica), permanece conectada à manutenção dos direitos mais fundamentais do homem, quais sejam, os direitos pétreos à vida, à liberdade e à segurança.

Findos os conceitos introdutórios - entendidos os fatores históricos que contribuíram para o desenvolvimento da sociedade contemporânea -, e percebendo as mudanças qualitativas das forças produtivas, cuja demanda conduz paulatinamente as organizações para a modificação dos processos de gestão que envolvem estes ativos intangíveis, passamos a buscar alternativas para o "como melhorar" a eficácia das políticas implementadas, neste caso, através da adoção de ferramentas de gestão do conhecimento orientadas à aprendizagem organizacional.

Diante desta perspectiva, percebe-se a relevância do tema em questão, cujo escopo baseia-se na proposta de utilização de ferramentas de gestão do conhecimento orientadas à aprendizagem e memória organizacionais para diminuição das barreiras de ambientação (socialização) vivenciadas por novos colaboradores da organização pesquisada.

Desta forma, o presente estudo busca responder à seguinte questão-chave de pesquisa: como melhorar os processos de socialização organizacional dos servidores policiais entrantes (recém-empossados) no Departamento de Polícia Federal, de maneira a reduzir os problemas enfrentados pelos servidores e maximizar os processos de aprendizagem organizacional?

Neste contexto, a hipótese que sustenta o estudo se baseia na possibilidade de utilização dos processos de mentoring e shadowing como ferramentas de gestão do conhecimento orientadas à aprendizagem individual, coletiva e organizacional, com o objetivo principal de diminuir as barreiras de ambientação enfrentadas pelos novos servidores entrantes no órgão, favorecendo a disseminação de uma cultura de aprendizagem e incrementando a memória organizacional.

Secundariamente, visa mapear as principais dificuldades diretamente relacionadas à socialização organizacional dos novos servidores policiais en- 
trantes no órgão e verificar, a partir da pesquisa realizada, a necessidade de adoção de programas de socialização pela organização pesquisada, onde estariam inseridos os processos de mentoria ou assessoramento para a melhoria do processo de ambientação e compartilhamento de conhecimentos entre servidores.

Para tanto, longe de querer esgotar o tema, apresenta o resultado de uma pesquisa qualitativa inicial efetuada por meio de entrevistas com servidores do órgão empossados a partir do concurso público realizado no ano de 2004, submetidos a perguntas relacionadas a três temas fundamentais, quais sejam: ambientação de servidores recém-empossados; imagem e cultura organizacional; e, por fim, supervisão e assistência ao novo servidor.

\section{Organização Pesquisada: Departamento de Polícia Federal}

O Departamento de Polícia Federal, instituído por lei como um órgão permanente, organizado e mantido pela União e estruturado em carreira, possui abrangência nacional e internacional, sendo composto por unidades centrais - através de 06 (seis) diretorias e correspondentes subestruturas, e por unidades descentralizadas - estas compostas por 27 (vinte e sete) superintendências regionais localizadas em todas as capitais brasileiras e no Distrito Federal, 88 (oitenta e oito) delegacias regionais situadas em outras localidades do país, e postos avançados em regiões de fronteira. Além das estruturas citadas, administra 13 (treze) adidâncias policiais e 10 (dez) escritórios de ligação internacionais.

Possui como atribuições, conforme o disposto no artigo $144, \S 1^{\circ} \mathrm{da}$ Constituição Federal, a apuração de infrações penais contra a ordem política e social ou em detrimento de bens, serviços e interesses da União ou de suas entidades autárquicas e empresas públicas; a prevenção e repressão do tráfico de entorpecentes, do contrabando e descaminho; o exercício das funções de polícia marítima, aeroportuária e de fronteiras; a função exclusiva de polícia judiciária da União; e da apuração de outras infrações penais cuja prática tenha repercussão interestadual ou internacional e exija repressão uniforme, conforme se dispuser em lei.

De acordo com o regimento interno do órgão, às diretorias centrais, quais sejam: diretoria executiva; de investigação e combate ao crime organi- 
zado; de logística; de pessoal; técnico-científica; e de inteligência; bem como suas estruturas subsequentes, sejam coordenações, divisões, serviços ou unidades, atribuem-se as tarefas de planejamento, normatização, controle, coordenação e suporte das atividades de natureza técnica ou policial.

Às unidades descentralizadas, compostas pelas superintendências regionais, delegacias regionais e postos avançados de fronteira, cabem as tarefas de natureza executiva, relativas à atividade-fim de polícia judiciária e administrativa, conforme atribuições definidas em lei.

Por fim, às adidâncias policiais e escritórios de ligação internacionais, de acordo com a Instrução-Normativa no 01/2005-DG/DPF, compete, dentre outras, as atribuições de assessorar o chefe da missão diplomática em assuntos de natureza policial; promover o intercâmbio de informações visando ao interesse comum de prevenção e repressão a ilícitos penais; e atuar como oficial de ligação com as organizações policiais do país de destino.

O quadro de recursos humanos do órgão se divide em cargos administrativos e cargos de natureza policial, como os de Agente de Polícia Federal, Escrivão de Polícia Federal, Delegado de Polícia Federal, Perito Criminal Federal e Papiloscopista Policial Federal, cujos processos de ingresso e formação são descritos a seguir.

\section{I DO INGRESSO E FORMAÇÃO DO POLICIAL FEDERAL}

A Instrução Normativa n ${ }^{\circ}$ 22/2010-DG/DPF, que regula as atividades de ensino e aprendizagem no âmbito do Departamento de Polícia Federal, estabelece em seu artigo $11^{\circ}$ que "as atividades de ensino promovidas pela Academia Nacional de Polícia são aquelas destinadas à formação, ao treinamento, à especialização e ao aperfeiçoamento de pessoal integrante ou não dos quadros da Polícia Federal”.

Neste contexto, o ingresso de servidores policiais no órgão - delegados, peritos, agentes, escrivães e papiloscopistas -, é realizado por meio de concurso público composto por duas etapas de seleção, quais sejam: $1^{a}$ etapa composta por a) prova objetiva, de caráter eliminatório e classificatório; b) prova discursiva, eliminatória e classificatória; c) exame de aptidão física; d) exame médico; e) avaliação psicológica, todas de caráter eliminatório. 
Em seguida, os candidatos aprovados nesta primeira etapa são convocados para a segunda fase do concurso, que consiste na realização do Curso de Formação Profissional com duração de cerca de 800 horas-aula e realizado na Academia Nacional de Polícia - sediada em Brasília/DF -, onde os futuros policiais, entre aulas teóricas e práticas, recebem o treinamento necessário para o início de suas funções.

Ao final do curso, os candidatos aprovados escolhem suas futuras lotações - em delegacias ou superintendências regionais de todas as regiões do país - de acordo com as vagas disponibilizadas no período e sua classificação final no curso de formação profissional. Por fim, com a posse e exercício no cargo, os novos servidores são iniciados na organização, onde, conforme aponta Chiavenato (2010, p. 180), integram-se os processos de socialização.

Após vencer os obstáculos do processo seletivo, os candidatos são admitidos na organização e se tornam novos membros dela e ocupantes de cargos. Contudo, antes que iniciem suas atividades, as organizações procuram integrá-los em seu contexto, condicioná-los às suas práticas e filosofias predominantes através de cerimônias de iniciação e de aculturamento social (CHIAVENATO, 2010, p. 180).

\subsection{DA SOCIALIZAÇÃO ORGANIZACIONAL DOS NOVOS SERVIDORES}

O estudo do conceito de socialização organizacional (atribuído na literatura como um sinônimo de socialização corporativa ou ambientação de funcionários) corresponde a um universo de natureza multidisciplinar, uma vez que concentra aspectos relevantes às áreas da psicologia, da sociologia $\mathrm{e}$ da administração onde, nesta última, permanece intimamente ligada à disciplina da gestão do conhecimento.

Segundo Almeida, Freitas e Souza (2011, p. 06), a gestão do conhecimento (GC) "refere-se à criação, explicitação e disseminação de conhecimentos no âmbito da organização", onde de acordo com Moresi (apud ALMEIDA; FREITAS; SOUZA, 2011, p. 06), "pode ser vista como um conjunto de atividades que busca desenvolver e controlar todo tipo de conhecimento em uma organização, visando à utilização na consecução de seus objetivos", justificando-se, nesta ótica, a importância do conceito de socialização organizacional para os processos de gestão do conhecimento. 
Van Maanen (apud SHINYASHIKI, 2002, p. 166), conceitua o processo de socialização organizacional como "o processo pelo qual uma pessoa aprende valores, normas e comportamentos exigidos, o que the permitirá participar como membro de uma organização". Em caráter similar, Chiavenato (2010, p. 181) interpreta a socialização organizacional de novos funcionários como "o processo pelo qual a organização procura marcar no novo participante a maneira de ele pensar e agir de acordo com os ditames da organização".

De acordo com Chiavenato (2010, p. 180), “a missão, a visão, os objetivos organizacionais, os valores e a cultura constituem o complicado contexto dentro do qual as pessoas trabalham e se relacionam nas organizações". Isto posto, evidencia-se a relevância dos processos de ambientação para a integração eficiente dos novos funcionários neste cenário onde, segundo Drucker (2001, p. 40), as organizações "precisam atrair e manter as pessoas, reconhecer e recompensá-las, motivá-las, atendê-las e deixá-las satisfeitas”. Sveiby (apud ROCHA NETO; ALONSO, 2011, p. 27), por sua vez, afirma que:

A contratação de novos funcionários é talvez o investimento mais importante da alta dirę̧ão das organizaçôes. Além disso, essa mudança de perspectiva implica na reciclagem dos colaboradores, para que suas mentes e capacidades criativas sejam mais integradas e convergentes com os objetivos organizacionais.

O processo de socialização organizacional, conforme Shinyashiki (2002) identifica, é formado por diversos componentes, quais sejam: o agente (fonte do aprendizado); o processo (a aprendizagem em si); o alvo (o socializado); e o resultado (o resultado da aprendizagem), assim como por quatro tarefas em que o socializado é submetido durante o processo: Domínio da tarefa: aprender como desempenhar o trabalho; Classificação do papel: desenvolver a compreensão do seu papel na organização; Aculturação: aprender a cultura da organização e ajustar-se a ela; Integração social: desenvolver relacionamentos com os colegas (SHINYASHIKI, 2002, p. 168).

Ressalta-se, ainda, como diz Van Maanen (apud SHINYASHIKI, 2002, p. 166), que o processo de socialização organizacional é um processo "contínuo durante toda a carreira do indivíduo na organização". Isto significa que, embora a entrada de um funcionário em uma organização seja o momento mais evidente do processo de socialização (ambientação) - e, por consequência, de maior repercussão para o futuro profissional do socializado -, 
trata-se de um processo de natureza cíclica, ocorrendo sempre que o funcionário modificar seu papel dentro da empresa, seja assumindo um novo posto de trabalho a partir de promoções na carreira, seja a partir de transferências ou mudanças de setor de atuação.

Neste conjunto, "a socialização pode ser compreendida como um processo de desenvolvimento de papéis, entendendo-se papel como o comportamento esperado de um indivíduo quando ocupa dada situação social" (SHINYASHIKI, 2002, p. 169). Ainda, segundo o autor (2002, p. 169):

A socialização refere-se ao processo pelo qual o individuo aprende a desempenhar os vários papéis sociais necessários para sua participação efetiva na sociedade. Isto quer dizer o modo como ele adquire o conhecimento, as habilidades e as disposiçôes que o capacitam a desempenhar seu papel de acordo com as expectativas dos outros enquanto muda de uma posição a outra na ordem social no decorrer do tempo.

\subsection{DOS ELEMENTOS ASSOCIADOS À SOCIALIZAÇÃO ORGANIZA- CIONAL}

A partir da análise dos conceitos apresentados, atenta-se para a complexidade envolvida em um processo de socialização organizacional, a qual permanece enredada a inúmeros elementos do ambiente corporativo, como a cultura organizacional, os processos de aprendizagem e os fatores intrapessoais, os quais, conjuntamente, modelam o universo relativo à ambientação do novo integrante à organização, seus valores, comportamentos, bem como ao conjunto de habilidades ou conhecimentos necessários para seu exercício funcional.

\subsubsection{Cultura Organizacional}

Maximiliano (2000, p. 105) comenta que "toda organização tem normas informais de conduta, que constituem uma legislação de usos e costumes que definem o comportamento correto" dos funcionários, influenciando fatores como a colaboração, qualidade dos serviços e a ética. Para o autor, cultura organizacional "compreende normas de cultura, valores, rituais e hábitos", onde "o comportamento dos membros é influenciado por essas normas, tanto quanto pelos regulamentos burocráticos". Para Schein (apud FLEURY; SAMPAIO, 2002, p. 287): 
Cultura organizacional é o conjunto de pressupostos básicos que um grupo inventou, descobriu ou desenvolveu ao aprender como lidar com os problemas de adaptação externa e integração interna e que funcionaram bem o suficiente para serem considerados válidos e ensinados a novos membros como a forma correta de perceber, pensar e sentir em relação a esses problemas.

Isto posto, verifica-se que a assimilação da cultura e a adaptação do funcionário às práticas nela implícitas decorrem de um processo bem sucedido de socialização organizacional, onde o novo colaborador, ora ambientado, passa a atuar de acordo com as normas de conduta, valores e hábitos exigidos, além de concorrer para sua perpetuação.

Assumindo este contexto, torna-se fundamental a compreensão dos gestores acerca da importância e influência da cultura organizacional no cotidiano da organização (SHINYASHIKI, 2002), e como aquela pode se manifestar de modo positivo ou negativo no comportamento dos funcionários e, em mesma medida, interferir nos resultados estratégicos alcançados pela organização.

Para tanto, “a inserção de processos sistemáticos de GC” (onde incluem-se os processos de mentoring e shadowing) "requer o desenvolvimento de uma cultura organizacional que reconheça, promova, valorize e recompense o compartilhamento de informações e conhecimentos" (ROCHA NETO; ALONSO, 2011, p. 10), a fim de que, conforme resume Xavier (2006, p. 13), a organização possa suprir as necessidades estratégicas oriundas de sua relação com os colaboradores, quais sejam:

Adesão - Ela precisa que cada um compreenda o que está acontecendo e aceite as mudanças que ela precisa realizar, isto é, precisa que haja adesão às suas politicas e estratégias. Direção - Precisa ainda que as pessoas dirijam seus esforços e talentos para os alvos certos, ou seja, que todos visem os mesmos objetivos, haja um alinhamento estratégico adequado. Empenho - Maiores desafios demandam mais empenho das pessoas, que elas realmente "vistam a camisa" e ajudem a empresa a lidar com as dificuldades. Eficiência - As pessoas estão sendo chamadas a aprender coisas novas - de modo rápido - para manter niveis de eficiência.

Nesta ótica, Nickel (2001) aponta a necessidade de alinhamento entre a cultura organizacional, os objetivos e as estratégias corporativas, de maneira a tornar factível a busca efetiva dos objetivos da organização, onde, 
de acordo com Oliveira (apud NICKEL, 2001, p. 39), "se a cultura organizacional estiver consistente com a estratégia, poderá ser considerada uma grande força da empresa”. Para Nickel (2001, p. 39):

Independentemente do enfoque dado para a estratégia organizacional, é importante ressaltar que em todo o processo de transformação de ideias estratégicas em ações estratégicas, além do processo intelectual individual ou coletivo de geração de propostas, existe o processo comportamental e social da obtenção de concordancia e apoio de outros individuos às propostas, a fim de que sejam implementadas.

\subsubsection{Processos de Aprendizagem}

Outro elemento relacionado à socialização organizacional - a aprendizagem - possui um caráter mais amplo do que o foco já citado do aprendizado da cultura corporativa pelo novo funcionário. Em verdade, versa sobre um extenso universo, podendo, de acordo com Fleury e Oliveira Jr. (2002), incidir em três níveis distintos, quais sejam: nível individual, do grupo e da organização.

Neste primeiro nível, do aprendizado individual, opera desde o modo como o funcionário (além da cultura) aprende sobre a estrutura e demais rotinas da organização, quanto aos aspectos relativos às habilidades, conhecimentos e expertises necessárias para o pleno desempenho de suas funções.

Neste sentido, Fleury e Oliveira Jr. (2002, p. 133) enfatizam que "todo processo de aprendizagem e criação de novo conhecimento começa no nível individual, isto é, nas pessoas. São as pessoas o ponto de partida e de sustentação para a ação estratégica da organização em seu dia-a-dia", fato que enfatiza a importância dos colaboradores como um ativo organizacional.

No segundo nível - da aprendizagem do grupo -, conceituada por Nonaka e Takeuchi (2008) pela característica da "externalização de conhecimentos", o processo de aprendizagem é compartilhado entre os integrantes a partir da socialização de conhecimentos tácitos "através do diálogo e da reflexão" (2008, p. 23), cujo produto final é sua conversão "em conhecimento transmissível e articulado" (2008, p. 23) e assimilado pelo grupo de funcionários.

Por fim, em nível organizacional, os conhecimentos compartilhados são absorvidos pela própria organização de forma implícita ou 
explícita, seja pela própria modificação da cultura corporativa (traduzida por hábitos, valores, normas ou comportamentos implícitos), seja através de elementos de natureza explícita, a partir da adoção de novas rotinas, procedimentos, normatizações, regulamentos etc.

Neste contexto, Probst e Buchel (1997 apud NEVES; FORMOSO, 2004, p. 4907) conceituam a aprendizagem organizacional como "um processo através do qual o conhecimento e as mudanças nos valores melhoram a habilidade em resolver problemas e a capacidade para a ação". Assim, embora o foco da socialização se baseie no aprendizado do funcionário entrante, cumpre ressaltar que tanto o socializado quanto o socializador são transformados pelo processo, como destaca (SHINYASHIKI, 2002, p. 168): "Assim que o socializado responde a um estímulo apresentado pelos outros, suas respostas constituem estímulos significantes para os responsáveis por sua socialização".

Em resumo, percebe-se que os variados fluxos de aprendizado a) do aprendizado individual; b) do individual ao grupo; c) do grupo à organização; d) alimentação da memória corporativa - podem ser "geridos" pela administração ao mapear os conhecimentos mandatórios para o alinhamento estratégico entre objetivos e competências essenciais, bem como pela criação de mecanismos de gestão que possibilitem a produção, armazenamento e disseminação do conhecimento, potencializando a inteligência e a memória organizacional.

\subsubsection{FATORES INTRAPESSOAIS}

Um terceiro elemento associado à socialização organizacional - os fatores intrapessoais - constitui o conjunto de experiências vivenciadas pelo indivíduo antes de seu ingresso na organização, seja a partir de sua formação, experiências e modelos mentais, seja através das expectativas e imagens que o indivíduo previamente possui sobre a organização.

Os modelos mentais, conceituados por Senge (2000, p. 201) como "imagens internas profundamente arraigadas sobre o funcionamento do mundo, que nos limitam a formas bem conhecidas de pensar e agir", constituem a dimensão cognitiva do conhecimento, onde "embora não possa ser articulada muito facilmente, essa dimensão do conhecimento dá forma ao modo como percebemos o mundo" (NONAKA; TAKEUSHI, 2008, p. 19). 
Nesta ótica, o próprio processo de aprendizagem se define pelo confronto dialético entre a nova informação recebida pelo indivíduo e os modelos mentais intrínsecos (experiências, ideais ou intuições), onde o produto final (como síntese) será o novo aprendizado, o qual, por sua vez, modificará o modelo mental anterior, em um ciclo de cognição contínuo.

Este fato revela a importância dos modelos mentais nos processos de aprendizado e socialização, uma vez que, por causa e a partir daqueles, cada indivíduo interpreta e reage à informação recebida de maneira singular. Como aponta Senge (2000, p. 202), "duas pessoas com modelos mentais diferentes podem observar o mesmo evento de forma diferente, pois vêem detalhes diferentes", onde "o mais importante é compreender que os modelos mentais são ativos - moldam nossa forma de agir”.

Além dos modelos mentais, outros aspectos que antecedem a entrada do candidato na organização, como as expectativas e imagens que o candidato possui sobre a empresa, influenciam diretamente no posterior processo de ambientação, uma vez que estes podem coincidir ou diferir da realidade encontrada pelo entrante na organização.

Estas dimensões (expectativas e imagens), segundo Shinyashiki (2002, p. 175), enfatizam "a importância da política de seleção quando descreve e explica ao candidato detalhes da organização, suas políticas e as características do novo papel organizacional que lhe caberá", onde "desencadeiam o processo de socialização por antecipação, que pode levar o candidato a rever seus comportamentos e valores". Ainda, esclarece o autor:

A admissão do candidato e o choque de realidade, com a afirmação ou negação das expectativas, vão influenciar o processo de socialização ou determinar a saida do novato. Quando os novos empregados entram na organização, vivenciam um choque de realidade ou surpresa, em especial quando seus pressupostos existentes em relação aos eventos apresentados não combinam com os que vigoram no novo ambiente (SHINYASHIKI, 2002, p. 175).

\subsubsection{Dos Objetivos e Problemas Relacionados à Socialização}

A partir deste "choque de realidade" apontado por Shinyashiki (2002), pode-se auferir uma gama de problemas derivados de um processo de socialização malsucedido, seja pela ausência de incentivos da própria orga- 
nização ou a partir da resistência de seus membros, seja pela não adequação do novo funcionário à cultura corporativa a ele apresentada, principalmente quando confrontada aos elementos intrapessoais, como os mapas mentais, valores, imagens ou expectativas.

Ainda neste sentido:

Esforços de recrutamento e seleção, palestras de integração de novos colaboradores, desenhos de sistemas de remuneração e implementação de mentores para acompanhar a vida de ocupantes de alguns cargos têm sido feitos isoladamente, muitas vezes sem o objetivo de organizar um processo sistemático de socialização do novo colaborador (SHINYASHIKI, 2002, p. 167).

Isto posto, questões envolvendo desmotivação, rotatividade de funcionários (turnover), ausência de sentido coletivo de identidade, ou ainda, a incompatibilidade entre as ações realizadas pelos colaboradores e os objetivos da empresa são problemas relacionados a organizações que não identificam a importância estratégica dos processos de socialização. Sobre este contexto, Schein e Wanous (apud SHINYASHIKI, 2002, p. 166) destacam que:

Falhas na condução no processo de socialização dos empregados podem provocar: Rejeiçãa, que pode levar o empregado a ser expelido da organização ou a canalizar suas energias contra os objetivos da empresa; Conformidade, que pode embotar sua criatividade e fazế-lo trabalhar de forma estéril e burocrática; Aumento do custo da rotatividade e absenteismo de pessoal.

Desta forma, verifica-se que os processos de socialização organizacional, além de introduzir o novo colaborador à cultura da organização e facilitar a aprendizagem dos conhecimentos necessários para a sua função, objetiva reduzir os problemas relacionados à ambientação, diminuindo custos envolvidos no recrutamento e seleção de pessoal e buscando o desenvolvimento do potencial competitivo da organização.

Diante do exposto, uma pergunta se torna fundamental: como as organizações devem lidar com este complexo ambiente que constitui o processo de socialização organizacional, uma vez que este se interliga a diversos elementos, como a cultura organizacional, os processos de aprendizagem (em seus três níveis - individual, do grupo e da organização) e os fatores intrapessoais (modelos mentais, expectativas e imagens)? 
Primeiramente, percebe-se como crucial a aceitação dos gestores acerca da imperiosa relevância dos processos de ambientação para a gestão estratégica da organização. Assim, torna-se possível, como resposta, a interferência da administração através da utilização de programas ou métodos de socialização organizacional (contidos nas políticas de gestão de pessoas), entre outras medidas de gestão, com o objetivo de buscar o alinhamento da cultura, aprendizagem e elementos intrapessoais, aos objetivos estratégicos da empresa.

Chiavenato (2010, p. 184), neste contexto, aponta alguns métodos de socialização utilizados pelas organizaçôes: o processo seletivo, que possibilita que o candidato "obtenha informações e veja com seus próprios olhos como funciona a organização e como se comportam as pessoas que nela convivem"; a tutoria, realizada a partir de processos como shadowing e mentoring, onde "o novo colaborador pode ligar-se a um tutor capaz de cuidar de sua integração na organização"; e os programas de ambientação, que constituem "o principal método de aculturamento dos novos participantes às práticas correntes da organização", ao combinar métodos como palestras e treinamentos. Ainda sobre os programas de ambientação:

É um programa formal e intensivo de treinamento inicial destinado aos novos membros da organização, para familiarizá-los com a linguagem usual da organização, com os usos e costumes internos (cultura organizacional), a estrutura da organização (as áreas ou departamentos existentes), os principais produtos ou serviços, a missão e os objetivos organizacionais (CHIAVENATO, 2010, p. 184).

Para apoio aos processos de socialização, podem ser utilizadas ferramentas de gestão do conhecimento orientadas à aprendizagem, tais como o treinamento de colaboradores; a utilização de processos de benchmarking, verificando programas de ambientação já implementados com sucesso por outras organizaçóes; processos baseados na tutoria, como mentoring e shadowing, maximizando os esforços na integração do novo colaborador.

\subsection{DOS PROCESSOS DE MENTORING E SHADOWING}

Conforme citado, os processos de mentoring e shadowing são ferramentas de gestão do conhecimento (GC) que podem ser utilizadas pelas organizações para o apoio aos processos de socialização (ambientação) de novos colaboradores, orientadas à aprendizagem individual (de forma direta) e organizacional (de maneira indireta). Na literatura acadêmica, diversos 
conceitos e definições destes processos são encontrados, bem como pesquisas de aplicação ou estudos de caso realizados, além do apontamento de suas similaridades e principais diferenças, propósitos e aplicações, conforme assinaladas a seguir:

\subsubsection{MENTORING}

Para Garvey (apud KRAUS, 2007, p. 34), “o termo mentoring está associado com 'iniciação', carreira, desenvolvimento pessoal e mudança. Seu foco mais comum é o da carreira profissional dentro de uma organização". De acordo com Kraus (2007, p. 34), "mentoring é entendido como a 'transferência de sabedoria'. É o processo pelo qual um indivíduo aprende com alguém com mais experiência num determinado campo, metaforicamente mais velho e mais sábio".

Souza e Rigo (2004, p. 6) conceituam "mentoria organizacional como o processo de assistência, técnica e psicossocial, dado por uma pessoa, que pode ser um superior, um par ou um subordinado, a outra, guiando-a e apoiando-a em sua carreira profissional", onde, de acordo com Bell (2005, p. 5), "alguém que ajuda outrem a aprender algo que seria, de outra maneira, aprendido não tão bem, mais lentamente ou de nenhuma maneira”.

Assim, o processo de mentoring se baseia na assistência prestada pelo mentor ao mentorando, fundamentada nas práticas de ensino e aprendizagem, onde segundo Santos, Tractenberg e Pereira (2005, p. 3), "a condição fundamental para que um mentor exerça esse papel é a disposição para compartilhar conhecimento". Em ótica inversa, "se uma organização incentiva a competição e a concorrência interna, os colaboradores serão vistos como concorrentes entre si, dificultando o compartilhamento de experiências e a realização de trabalhos em equipe" (ROCHA NETO; ALONSO, 2011, p. 55), desfavorecendo os processos de socialização organizacional e as iniciativas de gestão do conhecimento.

Neste sentido, os autores apontam que, para o sucesso do processo de mentoring, são fundamentais a "confiança; comprometimento; interesse mútuo; comunicação para troca de experiências; autoconsciência" (ROCHA NETO; ALONSO, 2011, p. 27). 
Para Santos, Tractenberg e Pereira (2005, p. 3):

A mentoria pode trazer beneficios tanto para o mentorando quanto para o mentor, uma vez que se constrói por meio de uma relação de (com)partilhamento de experiências. A diversidade de situaçôes profissionais com as quais mentor e mentorando se deparam ao longo desse processo é capaz de mobilizar novas competências em ambos, que aprendem com esse relacionamento.

De maneira a maximizar estes benefícios, denota-se que os processos de mentoring podem ser instituídos formalmente pela organização, inseridos nos programas de ambientação, onde primeiramente deverão ser selecionadas quais as competências fundamentais para o desempenho de determinada função e, após, realizar o recrutamento dos funcionários que detêm tais competências e desejam exercer a função de mentor/tutor dos novos colaboradores. Zey (apud SOUZA; RIGO, 2004, p. 6), neste sentido, aponta diferentes níveis de colaboração do mentor neste processo:

No primeiro, o mentor exerce o papel de professor, investindo seu tempo ao dar instruções e informações ao mentorado. No segundo nível, o mentor presta um suporte pessoal agindo como conselheiro e, portanto, influenciando também na vida pessoal do mentorado. O terceiro nível é o da intervenção organizacional, no qual o mentor pode usar inclusive de sua reputação para interceder pelo mentorado. No quarto e último nível, o mentor apoia e recomenda o mentorado para promoção aumentando a responsabilidade de ambos frente ao grupo social ou organizacional.

Em resumo, a aplicação dos processos baseados em mentoring objetiva proporcionar diversos benefícios estratégicos à organização, relativos aos processos de aprendizagem individual e coletiva (fluxo de conhecimento), redução dos custos de seleção (ao minimizar a rotatividade de funcionários), disseminação da cultura organizacional (criando um sentido coletivo de foco e identidade) e a efetiva socialização organizacional dos novos colaboradores (integrando-os ao cotidiano da organização).

Segundo Kraus (2007, p. 34):

1) "A potência do mentoring repousa no conhecimento específico e na sabedoria do mentor"; 2) "mentoring orienta e ensina"; 3) "mentores são uma espécie de mestre, pessoas com ampla experiência em determinada área, com mais anos de casa, e que demonstram interesse e disposição para colaborar no avanço da carreira de principiantes"; 
4) "mentoring focaliza a carreira, representa e transmite missão, visão e valores da empresa"; 5) "mentoring tende a reproduzir os padrões, valores e visão da organização".

\subsubsection{SHADOWING}

Os processos de shadowing objetivam os mesmos resultados da mentoria, diferindo-se conceitualmente pela metodologia empregada. Para Balceiro e Ávila (2003, p. 13) "shadowing consiste em alocar um profissional para seguir de perto um outro que detenha grande quantidade de conhecimentos tácitos, de forma a permitir que parte deste conhecimento seja retida pelo seguidor". Em mesmo sentido, Carvalho et al (2007, p. 21) aponta esta característica principal dos processos de shadowing - a observação direta - como o fator essencial que o diferencia dos processos de mentoring. Segundo os autores:

Shadowing ou sombra éum meio de capturar o conbecimento tácito, através da observação diária das atividades de um empregado. Esta ferramenta auxilia no aprendizado de uma dinâmica organizacional, a partir da análise sistemática das funções e comportamentos explicitados pelos colaboradores dessa organização (CARVALHO et al, 2007,p. 21).

Desta forma, o processo de shadowing apresenta aos participantes inúmeros benefícios onde, por parte do socializador, "permite que a pessoa observada possa refletir sobre suas habilidades e competências, superando-as" (CARVALHO et al., 2007, p. 22), e na parte do socializado, proporcionando a oportunidade de observar alguém 'em ação'; Oportunidade de captar o conhecimento tácito através da observação do dia-a-dia; Oportunidade de fazer perguntas para alguém enquanto esta pessoa realmente executa seu trabalho; Oportunidade de investigar alguma de suas suposições sobre esse campo particular de trabalho (CARVALHO et al., 2007, p. 22).

Isto posto, a utilização de ambas as ferramentas - mentoring e shadowing - como ferramentas de apoio à ambientação de funcionários entrantes, objetivam oferecer à organização a assistência aos novos colaboradores durante o processo de socialização, bem como o estímulo à troca e, consequentemente, à perpetuação de conhecimentos tácitos dos servidores, favorecendo os demais processos de gestão do conhecimento e evitando o surgimento de problemas derivados de uma ambientação mal sucedida. 


\section{Metodologia Utilizada}

Como metodologia de pesquisa, optou-se, como introdução ao tema, por realizar uma pesquisa inicial qualitativa, realizada por meio de entrevistas com dezesseis servidores (entre agentes, delegados, escrivães, peritos criminais e papiloscopistas) empossados no órgão a partir do concurso público realizado no ano de 2004, e lotados no edifício-sede do DPF em Brasília/DF. A escolha do universo pesquisado se justifica pelo grau de experiência dos pesquisados, uma vez que todos os servidores submetidos à entrevista vivenciaram sua primeira lotação em unidades descentralizadas (delegacias regionais ou superintendências de diversas regiôes do país), o que enriquece a experiência dos mesmos no tema em questão (socialização organizacional) e os possíveis problemas decorrentes.

Para tanto, a pesquisa foi construída através da realização de entrevistas com o universo pesquisado, formado por dez perguntas subdivididas em três temas fundamentais, quais sejam: I) Ambientação e integração de servidores; II) Imagem e cultura organizacional; III) Supervisão e assistência ao novo servidor.

\section{Tema I: ambientação e integração de servidores:}

- Como você considera a integração entre antigos e novos policiais?

- Vocêjá esteve envolvido, durante o início de sua carreira, em situações que não sabia como proceder? Em caso positivo, sentiu-se à vontade para pedir ajuda a colegas com maior experiência?

- Quais dificuldades você vivenciou no início de sua carreira?

\section{Tema II: imagem e cultura organizacional:}

- A imagem que vocêt tinha da instituição antes de sua posse se manteve igual após o início do seu trabalho?

- Em caso negativo, quais os motivos da mudança?

\section{Tema III: supervisão e assistência ao novo servidor:}

- O que vocêpensa sobre a presença de um servidor mais experiente que atue como um "tutor" para os novos policiais?

- Vocêsentiu necessidade de participar de um "programa de boas-vindas" no início de sua atuação como policial? 
- Você participou de alguma espécie de programa institucional para chegada de novos policiais?

- Você enxerga alguma relação entre a qualidade do início da carreira e o futuro profissional do servidor? Comente.

Neste contexto, o objetivo principal da pesquisa realizada é buscar respostas para a seguinte pergunta chave: como melhorar os processos de socialização organizacional dos servidores entrantes no Departamento de Polícia Federal, de maneira a maximizar os processos de aprendizagem organizacional?

Em complemento, busca comprovar a hipótese de que a adoção dos processos de mentoring e shadowing como ferramentas de gestão do conhecimento orientadas à aprendizagem individual e organizacional pode influir de maneira positiva no processo de ambientação de novos servidores, minimizando os problemas dela decorrentes e estimulando a troca de informações entre antigos e novos policiais.

Desta forma, através da realização de entrevistas com servidores, o presente trabalho visa mapear as principais dificuldades relacionadas à socialização organizacional vivenciadas pelos novos policiais entrantes no órgão e apontar, sob sua ótica, a possibilidade de adoção de programas institucionais de ambientação, com a utilização de processos de mentoring e shadowing para melhorias da socialização e troca de conhecimentos entre servidores.

\section{Resultados da Pesquisa}

A pesquisa, através da realização de entrevistas, apresentou os seguintes resultados, relacionados a partir das perguntas realizadas sob as três subdivisões de temas apresentados, quais sejam: ambientação dos servidores, imagem e cultura organizacional, e, por fim, supervisão e assistência ao novo servidor.

\section{Tema I - Ambientação e integração de servidores:}

- Como você considera a integração entre antigos e novos policiais? Todos os servidores entrevistados consideraram como fundamental a integração entre policiais experientes e novatos, como forma de aprendizagem e acúmulo de experiência no serviço policial. Entretanto, $25 \%$ dos entrevistados relataram que, por vezes, existem dificuldades de integração entre colegas, onde foram apresentados os se- 
guintes motivos: diferenças de percepção sobre o órgão; diferenças etárias; resistência por alguns servidores mais antigos.

- Vocêjá esteve envolvido, durante o início de sua carreira, em situaçôes que não sabia como proceder? Em caso positivo, sentiu-se à vontade para pedir ajuda a colegas? A maior parte dos entrevistados (75\%) afirmou ter se envolvido em situações de trabalho em que não sabia como proceder, afirmando como causa principal a falta de experiência no trabalho policial. A mesma quantidade de entrevistados relatou, igualmente, que se sentiu à vontade para perguntar aos policiais mais experientes a melhor forma de proceder frente a estas situações, aproveitando positivamente o conhecimento dos policiais mais antigos.

- Quais dificuldades você vivenciou no inicio de sua carreira? Todos os servidores que relataram algum grau de dificuldade no início da carreira (mais de $75 \%$ dos entrevistados) pontuaram problemas como: desconhecimento das rotinas da atividade policial, desconhecimento das atividades desempenhadas pelos setores, insegurança para a tomada de decisão, medo de cometer erros por inexperiência, distância dos amigos e familiares, diferenças culturais e dificuldade de ambientação na nova cidade.

\section{Tema II - Imagem e cultura organizacional:}

- A imagem que você tinha da instituição antes de sua posse se manteve igual após o início do seu trabalho? Em caso negativo, quais os motivos da mudança? Todos os entrevistados afirmaram que a imagem que possuíam da organização antes da aprovação no concurso modificou-se após a entrada no órgão. Perguntados sobre os motivos, foram citados os seguintes fatores: baixo sentimento de valorização pelo desempenho das funções, complexidade no relacionamento entre as categorias funcionais, ausência de perspectivas de crescimento profissional.

\section{Tema III - Supervisão e assistência ao novo servidor:}

- O que vocêpensa sobre a presença de um servidor mais experiente que atue como um "tutor" para os novos policiais? Você sentiu necessidade de participar de um "programa de boas-vindas" no inicio de sua atuação como policial? Todos os entrevistados responderam de forma positiva, entendendo a possibilidade da presença de servidores experientes para apoio à iniciação dos novos policiais, 
bem como a necessidade de participação em programas oficiais de ambientação ou socialização, onde foram feitas as seguintes considerações: "ganho de experiência", "maior aprendizagem"; "ganho de tempo na adaptação ao trabalho", "conhecimento das rotinas e estrutura do órgão", "conhecer os colegas de trabalho".

- Você participou de alguma espécie de programa institucional para chegada de novos policiais? Em relação a programas de ambientação, $75 \%$ dos entrevistados responderam não ter participado de nenhuma espécie de programa, apenas em "conversas informais". Cerca de $25 \%$, entretanto, afirmaram ter sido submetidos a um "estágio supervisionado", onde realizaram tarefas em diversos setores, por um período que variou de um a dois meses.

- Você enxerga alguma relação entre a qualidade do início da carreira e o futuro profissional do servidor? Comente. Cerca de $50 \%$ dos servidores entrevistados responderam positivamente, $25 \%$ responderam de forma negativa e $25 \%$ consideraram a questão como indiferente. Aos que responderam como positiva a afirmação, foram citados como possíveis consequências do início da carreira fatores como "possibilidade de motivação ou desmotivação", "reflexos na qualidade nos serviços prestados”.

\section{Consideraçốes Finais}

A partir dos resultados da pesquisa, denota-se a presença de um ambiente propício para a adoção de programas institucionais de ambientação de novos servidores, bem como para utilização dos processos de mentoring e shadowing como ferramentas de gestão do conhecimento orientadas à aprendizagem e voltadas à socialização organizacional de novos funcionários.

Alguns pontos fundamentais extraídos das entrevistas embasam esta conclusão, onde os pesquisados consideram como fundamental a integração entre novos e antigos servidores para a aprendizagem das rotinas e expertises necessárias para a prática policial, bem como pelo relato de problemas de ambientação vivenciados no início da carreira, como "falta de experiência", "insegurança na tomada de decisão" e "desconhecimento de atividades", os quais se coadunam com os objetivos de utilização das ferramentas de gestão do conhecimento disponíveis à organização. 
A maior parte dos pesquisados afirmou, igualmente, ter se envolvido no início da carreira em situações de trabalho em que não sabia como proceder, onde se percebeu um grau de abertura positivo para a solicitação de apoio aos policiais mais experientes, visando buscar a melhor forma de proceder frente a estas situações consideradas difíceis. Em mesma medida, foi relatada e sentida a necessidade (por parte dos entrevistados) de participar de programas institucionais de ambientação, visando minimizar os problemas vivenciados.

Por fim, pela análise teórica realizada, quando analisado o ambiente conjuntural instável e competitivo em que atuam as organizações, bem como as mudanças do perfil das forças de trabalho nas últimas décadas, percebe-se que a posse deste ativo (conhecimento) vem alterando as relações entre a organização e o trabalhador, conduzindo a contínuas adaptações nos mecanismos de gestão aplicados e tornando cada vez mais relevante a aplicação da gestão do conhecimento e suas ferramentas para a manutenção do potencial competitivo das organizações.

Como limitações da pesquisa, destaca-se o pequeno universo de pesquisa, formado por dezesseis servidores dos diversos cargos que compõem o quadro de servidores policiais do Departamento de Polícia Federal, o que, pelo número reduzido da amostra, prejudica a generalização dos resultados apresentados. Como sugestão de pesquisas futuras, aponta-se a possibilidade de refazer a presente pesquisa em um espectro amostral superior, assim como em realizar comparativos entre os diversos concursos públicos realizados ou por cada cargo pesquisado.

Por fim, apontou-se a relevância dos processos de socialização organizacional para a atração, retenção e direcionamento estratégico dos novos funcionários, os quais evidenciam os inúmeros benefícios colhidos pela organização na utilização dos processos de mentoring e shadowing para disseminação da cultura organizacional entre os novos servidores, construindo um sentido coletivo de identidade e incentivo à troca de experiências e criação de conhecimento, buscando dirimir os problemas de ambientação derivados e auxiliando na construção da memória da organização.

Luciano d`Escragnolle Cardoso

Agente de Polícia Federal, Especialista em Inteligência Estratégica, Mestrando em Gestão do Conhecimento e da TeCNOLOGIA DA INFORMAÇão .

E-MAIL: CARDOSO.LEC@DPF.GOV.BR 


\begin{abstract}
Mentoring and Shadowing Processes as a Knowledge Management Tool Oriented for Socialization of New Servers on the Brazilian Federal Police

The purpose of this paper is to investigate the main difficulties faced by organizational socialization employees recently inducted into the Federal Police Department, with the aim of pointing out the possibility of using the processes of mentoring and shadowing as tools for knowledge management-oriented learning organization, acting through the systematic sharing of experiences and promoting the socialization of knowledge between old and new servers. To do so, presents the results of a qualitative research through interviews with police officers sworn servers in the organ from the public tender conducted in 2004, aiming to identify the most common difficulties of socialization (setting) experienced by these, and how the processes of mentoring and shadowing can help reduce the barriers faced by the incoming server in the organ, as well as acting in the spread of the internal culture of learning and knowledge management, adding the knowledge produced as a increase for the organizational memory.
\end{abstract}

KEYWORDS: Shadowing; Mentoring; Knowledge management; Organizational learning; Organizational memory; Organizational socialization.

\title{
REFERÊNCIAS
}

ALMEIDA, Mario de Souza; FREITAS, Claudia Regina; SOUZA, Irineu Manuel de. Gestão do Conhecimento para Tomada de Decisão. São Paulo: Atlas, 2011.

BALCEIRO, R. B.; ÁVILA, G. M. A gestão de pessoas para o profissional do conhecimento. Anais KM Brasil: São Paulo, 2003.

BELL, Chip. Mentor e Aprendiz. São Paulo: M Books do Brasil, 2005.

CARVAlHO, Márcia Maria de; PACHECO, Ana Paula Gonçalves; SANTOS, Sabrina de Lima dos; SILVA, Valéria de Paula. Plano de transferência de conbecimento tácito e critico entre os membros da equipe do centro nacional de gerência de telecomunicações da Petrobrás. Rio de Janeiro. 2007. Especialização (Pós-Graduação em Gestão do Conhecimento e Inteligência Empresarial) Universidade Federal do Rio de Janeiro, Rio de Janeiro. 2007.

CHIAVENATO, Idalberto. Gestão de Pessoas: O Novo Papel dos Recursos Humanos nas Organizações. Rio de Janeiro: Elsevier, 2010. 
DRUCKER, Peter Ferdinand. O Melhor de Peter Drucker: Obra Completa. Tradução de Maria L. Leite Rosa, Arlete Simile e Edite Sciuli. São Paulo: Nobel, 2001.

FLEURY, Maria Teresa Leme; OLIVEIRA JR, Moacir de Miranda. Aprendizagem e Gestão de Conhecimento. In: FLEURY, Maria Teresa Leme. (Org.). Aspessoas na Organização. São Paulo: Editora Gente, 2002.

FLEURY, Maria Teresa Leme; SAMPAIO, Jader dos Reis. Uma Discussão sobre Cultura Organizacional. In: FLEURY, Maria Teresa Leme. (Org.). Aspessoas na Organização. São Paulo: Editora Gente, 2002.

KRAUS, Rosa R. Coaching Executivo: A Conquista da Liderança. São Paulo: Nobel, 2007.

MAXIMILIANO, Antonio Cesar Amaru. Introdução à Administração. São Paulo: Atlas, 2000.

NEVES, R. M.; FORMOSO, C. T. Construção de um Modelo para Aprendizagem Organizacional fundamentado na Aprendizagem Baseada em Problemas. In: XXIV Encontro Nacional de Engenharia de Produção. Anais..... Florianópolis: 2004, p. 4907-4914.

NICKEL, D. C. Estratégias Organizacionais, Processo Seletivo e Integração Normativa: Estudo de Caso na Indústria Automobilística. Revista FAE, Curitiba, v. 4, n. 2, p. 37-52, mai./ago., 2001.

NONAKA, Ikujiro; TAKEUSHI, Hitotaka. Gestão do Conhecimento. Tradução de Ana Thorell. Porto Alegre: Bookman, 2008.

ROCHA NETO, Ivan; ALONSO, Luiza Beth Nunes (Orgs.). Introdução à Gestão do Conhecimento: O Olhar da Complexidade. Brasília: Paralelo 15, 2011.

SANTOS, Edméa Oliveira dos; TRACTENBERG, Leonel; PEREIRA, Máira. Mentoria: a formação inicial e continuada dos professorestutores no programa FGV Online. 2005. Disponível em: <http:// www.abed.org.br>. Acesso em: 30 mai. 2012.

SCHLINDWEIN, S. L. Prática sistêmica para lidar com situações de complexidade. Anais do I Congresso Brasileiro de Sistemas. Ribeirão Preto: nov., 2005.

SENGE, Peter. A Quinta Disciplina. São Paulo: Best Seller, 2000. 
SHINYASHIKI, Gilberto. O Processo de Socialização Organizacional. In: FLEURY, Maria Teresa Leme. (Org.). As pessoas na Organização. São Paulo: Editora Gente, 2002.

SOUZA, Denise Clementino de; RIGO, Ariadne Scalfoni. Mentoria na perspectiva daquele que aprende: o caso de uma empresa multinacional de consultoria. 2004. Disponível em: <www.ead.fea.usp.br/semead>. Acesso em: 30 mai. 2012.

XAVIER, Ricardo de Almeida Prado. Gestão de Pessoas na Prática: Desafios e Soluçôes. São Paulo: Editora Gente, 2006.

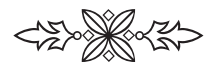

